\title{
Study on Molecular Tracking and Bioactivity of Glucocerebroside Isolated from Radish (Raphanus sativus L.)
}

\author{
Guifeng $\mathrm{Li}^{1, *}$, Guixin $\mathrm{Li}^{2}$, Haixia Fan ${ }^{1}$, Mingdi Xia ${ }^{3}$, Jiangsheng Mao ${ }^{4}$, Yebing Chen ${ }^{4}$, Changying Guo ${ }^{4}$ \\ ${ }^{1}$ Shandong Lvyuan Agricultural Science and Technology Research Institute, Weifang, China \\ ${ }^{2}$ Affiliated Hospital of Weifang Medical College, Weifang, China \\ ${ }^{3}$ Center for Reproductive Medicine, Shandong Provincial Hospital, Shandong University, Jinan, China \\ ${ }^{4}$ Institute of Agricultural Quality Standards and Testing Technology Research, Shandong academy of agricultural sciences, Jinan, China \\ *Corresponding author: tianshu1858@sina.com
}

Received September 09, 2014; Revised November 01, 2014; Accepted November 13, 2014

\begin{abstract}
The cruciferous herb Weixian radish (Raphanus sativus L.), also known as Lai Fu, is a popular type of edible vegetable. The present paper describes the molecular tracking and bioactivity of glucocerebroside isolated from Weixian radish for the first time. Methanol extraction was carried out by using silica gel, Sephadex LH-20 and RP-C18 column chromatography. Based on their structures, the two compounds were determined to be 1-O- $(\beta$-Dglucopyranosyl)-(2S, 3S, 4R, 8E)-2-[(2'R)-2'-hydroxyl-tetracos-15'-enoyl amino]-8-octa-decene- 1, 3, 4-triol (glucocerebroside). The glucocerebroside could inhibit the growth of BEL-7402 cancer cells and induce apoptosis in these cells.
\end{abstract}

Keywords: Raphanus sativus L., glucocerebroside, molecular tracking, bioactivity

Cite This Article: Guifeng Li, Guixin Li, Haixia Fan, Mingdi Xia, Jiangsheng Mao, Yebing Chen, and Changying Guo, "Study on Molecular Tracking and Bioactivity of Glucocerebroside Isolated from Radish (Raphanus sativus L.)." Journal of Food and Nutrition Research, vol. 2, no. 12 (2014): 914-917. doi: 10.12691/jfnr-2-12-9.

\section{Introduction}

Raphanus sativus L., also known as Weixian radish, is a vegetable commonly used for nutritional and medicinal purposes. Weixian was the name of Weifang city of the Shandong Province before its liberation. Many famous specialty items are associated with Weifang, such as the kite, New Year picture, and Weixian radish. Weixian radish is known for its excellent nutritional and medicinal value; it is sweet and juicy with a succulent, crisp and slightly spicy flavor $[1,2,3]$. The most popular part for eating is the napiform taproot, although the entire plant is edible and the tops can be used as a leaf vegetable. Roots are eaten raw or cooked or preserved by storage, pickling, canning or drying [4,5]. Medicinally, it is helpful for treating cough, excessive phlegm and fever [2]. It has been used as a traditional therapeutic medicine for weakness of the spleen and the stomach, hemorrhinia, hemoptysis and other conditions. The main pharmacological effects of Weixian radish are its anti-inflammatory and anti-bacterial effects, as well as the prevention of gallstone formation [1,2,3]. It is also used to treat senile constipation, hypertension, diabetes and vaginitis. Modern research shows that eating radish regularly can reduce blood lipid levels, soften blood vessels, stabilize blood pressure and prevent coronary heart disease, arteriosclerosis, cholelithiasis and other diseases [1,2,3]. It also can promote hemoglobin production and improve the blood concentration of nitrosamines, such that macrophage destruction of cancer cells is increased by $2-4$ times and cancer cells can be reconverted to normal cells $[1,2,3]$.

Cerebroside, which is low content and great activity of endogenous substances, exist in animals, plants, fungi, and marine life in the category. It belongs to the glycosphingolipid, is a glycoside formed by monosaccharide or oligosaccharides with hydroxyl of ceramide end [6]. As the cell membrane structure composition, cerebroside is a widespread component, including many kinds of galactocerebroside, glucocerebroside and 1actosylceramide. This kind of material have been discovered mainly exists in brain tissue of mammals, as well as in the membrane organization of heart, liver and erythrocyte, membrane of sea anemones, sponges and sea cucumber, marine plants, Land animals, insects, bacteria, a variety of plants proposal $[6,7,8]$. The present paper describes the molecular tracking and bioactivity of glucocerebroside isolated from Weixian radish for the first time.

Although clinical practice has demonstrated the anticancer actions of Weixian radish, its chemical constituents have not been reported. Therefore, we studied the chemical composition of Weixian radish and for the first time isolated and identified two compounds present from this important vegetable. 


\section{Experimental}

\subsection{Chemicals}

Petroleum ether and chloroform were purchased from Guangcheng Chemical Co., Ltd. (Tianjin, China). Methanol and ethyl acetate were purchased from Siyou Fine Chemical Co., Ltd. (Tianjin, China). Ethanol and sulfuric acid were purchased from the fine chemical plant of the Economic Development Zone of Laiyang in Shandong Province.

\subsection{Plant Material}

Plant materials were collected on December 18, 2008 from Weifang City, China. The root tubers of Weixian radish were washed, oven-dried at $50^{\circ} \mathrm{C}$, and crushed in 20 mesh sieve. A voucher specimen was identified by Professor Li Fazeng, doctoral tutor of the Life Science Department of Shandong Normal University, and deposited in the research group (ID: zxs-188).

\subsection{Chromatography Materials}

Column chromatography silica gel (200-300 mesh) and GF254 (10-40 $\mu \mathrm{m}, 0.25 \mathrm{~mm}$ ) were purchased from Qingdao Marine Chemical Plant (Qingdao, China). Sephadex LH-20 gel column and Novepak C18 reversed phase column were purchased from Waters Co. (Milford, MA, USA).

\subsection{Extraction and Separation}

Dried and powdered root stems of Raphanus sativus L. (3 kg) were extracted with methanol at room temperature four times for 5 days each time. The combined extract was vacuum concentrated to $70 \mathrm{~g}$. The concentrated methanol extract was diluted with distilled water and extracted with petroleum ether, ethyl acetate, and n-butanol, individually, 3 times each. After determining the concentration of the organic layer, we obtained 31.85 g extract in petroleum ether, 11.40 g extract in ethyl acetate, and $22.30 \mathrm{~g}$ extract in n-butanol. A combination of size exclusion chromatography, silica gel chromatography, and high performance liquid chromatography (HPLC) of the plant extract in ethyl acetate led to the isolation of two compounds.

\subsection{Spectroscopy}

All nuclear magnetic resonance (NMR) spectra were recorded on Bruker AVANCE $600\left(600.15 \mathrm{MHz}\right.$ for ${ }^{1} \mathrm{H}$ and $150.9 \mathrm{MHz}$ for ${ }^{13} \mathrm{C}$ ) at room temperature $(298.0 \mathrm{~K})$ using 5-mm sample tubes. Chemical shifts were given in parts per million (ppm) and were referenced to the TMS for both nuclei. High-resolution electrospray ionization mass spectrometry (HR ESI-MS) was conducted using a LTQ Obitrap XL spectrometer from Thermofisher Scientific (Waltham, MA, USA).

\subsection{Effect of Compound 1 on the Proliferation of Liver Cancer Cells}

One hundred-microliter aliquots of BEL-7402 cells at a concentration of $1 \times 10^{5} / \mathrm{ml}$ were seeded into 96 -well plates. The culture medium (10\% fetal bovine serum and RPMI1640 medium, GIBCO) was replaced after 24 hours. The experimental group was exposed to 10,20 , 40, or $80 \mu \mathrm{g} / \mathrm{L}$ glucocerebroside (compound 1), and control cells were grown in culture medium only. Blank control wells with no cells contained culture medium only. Three replicates were used for each condition. Culture plates were kept in an incubator maintained at $37^{\circ} \mathrm{C}$ with $5 \% \mathrm{CO} 2$ and saturated humidity for $24,48,72$, or 96 hours. At the end of each incubation period, $20 \mu \mathrm{l}$ of $5 \mathrm{~g} / \mathrm{L}$ MTT solution was added to each well, and the plates were returned to the incubator for another 4 hours of culture before being centrifuged (1200 rpm for $10 \mathrm{~min}$ ). The supernatant in each well was removed, and $150 \mu$ l dimethyl sulfoxide (DMSO) was added to each well. After plates were shaken on a micro-oscillator for $5 \mathrm{~min}$, the absorbance (i.e., optical density [OD]) of each well was detected by an automatic enzyme apparatus with an excitation wavelength of $570 \mathrm{~nm}$ and an emission wavelength of 620 $\mathrm{nm}$. The rate of cell growth inhibition was calculated as follows and analysis of variance was used to identify significant differences.

$$
\begin{aligned}
& \text { Inhibition rate } \\
& =\frac{O D_{\text {control group }} I O D_{\text {exp erimental group }}}{O D_{\text {control group }} I O D_{\text {blank group }}} \times 100 \%
\end{aligned}
$$

\subsection{Ultrastructure Morphology Change of Liver Cancer Cells Exposed to Compound 1}

Three-milliliter samples of BEL-7402 cells at a concentration of $1 \times 10^{5}$ cells $/ \mathrm{ml}$ were transferred to culture flasks and incubated at $37^{\circ} \mathrm{C}$ until growth of the walls of the flasks was observed. Another $3 \mathrm{ml}$ of culture medium containing $40 \mu \mathrm{g} / \mathrm{L}$ compound 1 was added, and the flasks were incubated for 24 hours. Then the cells were washed out of bottle, centrifuged at $1000 \mathrm{rpm}$ for 10 minutes, and washed twice with phosphate-buffered saline (PBS). Cells were then fixed in $4 \%$ glutaraldehyde overnight, centrifuged at $2000 \mathrm{rpm}$ for 10 minutes, and mixed with $2 \%$ agarose. After cooling, $1-\mathrm{mm}^{3}$ agarose blocks were cut and fixed for 3 hours with 1\% osmium tetroxide. Blocks were washed with PBS completely and then dehydrated using gradient alcohol dehydration. Dried blocks were embedded in embedding medium (ethoxyline resin, Wuxi Resin Factory) and then sectioned using a microtome (LEICA). Double staining of uranyl acetate and lead citrate was carried out for observation by electron microscopy.

\section{Results and Discussion}

\subsection{Compound 1}

Compound 1 was obtained as a white crystalline powder (in methanol), and upon its dissolution, 10\% sulfuric acid solution became dark purple. Compound 1 was soluble in methanol, slightly soluble in chloroform, and insoluble in petroleum ether or acetone. Its molecular formula was determined to be $\mathrm{C}_{48} \mathrm{H}_{91} \mathrm{NO}_{10}$ on the basis of the HR-ESI-MS $[\mathrm{M}+\mathrm{H}]^{+}, \mathrm{m} / \mathrm{z} 842.6738$ (calculated for $\mathrm{C}_{48} \mathrm{H}_{92} \mathrm{NO}_{10}$ : 842.6716). In the ${ }^{13} \mathrm{C} \mathrm{NMR}$ data, the carbon resonances at $\delta 103.4(\mathrm{C}-1 "), 73.3\left(\mathrm{C}-2^{\prime \prime}\right), 76.4(\mathrm{C}-3 ")$, 69.9 (C-4"), 76.8 (C-5"), and 60.9 (C-6") confirmed the glucopyranose moiety. The $\beta$-configuration of the 
glucoside unit was indicated by an anomeric proton at $\delta$ $4.14\left({ }^{1} \mathrm{H}, \mathrm{d}, \mathrm{J}=7.8 \mathrm{~Hz}, \mathrm{H}-1 "\right)$. In ${ }^{1} \mathrm{H}$ NMR, $\delta 0.84$ (t, 6H, J $\left.=6 \mathrm{~Hz}, 2 \times \mathrm{CH}_{3}\right)$ showed that a long-chain fatty was present and $\delta 1.24$ was the signal for a range of methylene protons. In ${ }^{13} \mathrm{C}$ NMR, $\delta$ 28.4 29.1 were carbon signals of methylene protons, indicating the presence of long-chain alkanes. Only two overlapping methyl signals were observed in both ${ }^{1} \mathrm{H}$ NMR and ${ }^{13} \mathrm{C}$ NMR, proving that both of the alkane structures had no branches. In ${ }^{13} \mathrm{C}$ NMR, $\delta 49.7$ was the carbon signal linked to the amide groups ($\mathrm{CH}-\mathrm{NH}-$ ), and this showed that two long chain aliphatic moieties were connected by an amide bond. Based on the above analysis, we concluded that this compound was a cerebroside, whose structure was a long-chain fatty acid (FAM) combined with a long-chain fatty amine (i.e., longchain base [LCB]). The NMR results for compound 1 also indicated the presence of olefinic functions $(\delta \mathrm{H} 5.32$ and 5.37, 4H; $\delta \mathrm{C}$ 129.2, 129.3, 129.5, 130.2). The above spectral data were basically identical with those previously reported in the literature[9]. Therefore, this compound was identified as 1-O-( $\beta$-D-glucopyranosyl)(2S, 3S, 4R, 8E)-2-[(2'R)-2'-hydroxyl-tetracos- 15'-enoyl amino]-8-octa-decene-1, 3, 4-triol, its structure is shown in Figure 1 and NMR data is listed in Table 1.

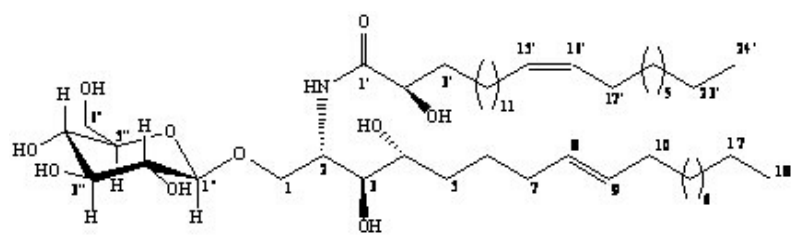

Figure 1. The construction of compound 1

Table 1. ${ }^{1} \mathrm{H}$ NMR and ${ }^{13} \mathrm{C}$ NMR (in DMSO-d6) of compound 1

\begin{tabular}{|c|c|c|c|c|c|}
\hline $\begin{array}{c}\text { Serial } \\
\text { No. }\end{array}$ & $\delta \mathrm{H}(\mathrm{ppm})$ & $\begin{array}{c}\delta \mathrm{C} \\
(\mathrm{ppm})\end{array}$ & $\begin{array}{c}\text { Serial } \\
\text { No. }\end{array}$ & $\begin{array}{c}\delta \mathrm{H} \\
(\mathrm{ppm})\end{array}$ & $\begin{array}{c}\delta \mathrm{C} \\
(\mathrm{ppm})\end{array}$ \\
\hline \multirow[t]{2}{*}{1} & $\begin{array}{c}3.65 \\
(1 \mathrm{H}, \mathrm{m})\end{array}$ & 68.8 & $1^{\prime}$ & - & 173.7 \\
\hline & $\begin{array}{c}3.79 \\
(1 \mathrm{H}, \mathrm{m})\end{array}$ & & $2^{\prime}$ & $\begin{array}{c}3.85 \\
(1 \mathrm{H}, \mathrm{m})\end{array}$ & 70.8 \\
\hline 2 & $\begin{array}{c}4.04 \\
(1 \mathrm{H}, \mathrm{m})\end{array}$ & 49.7 & $3^{\prime}$ & $\begin{array}{c}1.49 \\
(1 \mathrm{H}, \mathrm{m})\end{array}$ & 34.2 \\
\hline 3 & $\begin{array}{c}3.37 \\
(1 \mathrm{H}, \mathrm{m}) \\
\end{array}$ & 74.0 & & $\begin{array}{c}1.60 \\
(1 \mathrm{H}, \mathrm{m})\end{array}$ & \\
\hline 4 & $\begin{array}{c}3.31 \\
(1 \mathrm{H}, \mathrm{m})\end{array}$ & 70.6 & $14^{\prime}, 17^{\prime}$ & $\begin{array}{c}1.98 \\
(4 \mathrm{H}, \mathrm{m})\end{array}$ & 26.5 \\
\hline \multirow[t]{2}{*}{5} & $\begin{array}{c}1.49 \\
(1 \mathrm{H}, \mathrm{m})\end{array}$ & 31.2 & $15^{\prime}, 16^{\prime}$ & $\begin{array}{c}5.32 \\
(2 \mathrm{H}, \mathrm{m}) \\
\end{array}$ & $\begin{array}{l}129.3, \\
129.5\end{array}$ \\
\hline & $\begin{array}{c}1.60 \\
(1 \mathrm{H}, \mathrm{m})\end{array}$ & & $-\mathrm{CH}_{2}$ & $\begin{array}{l}1.24 \\
(\mathrm{~m})\end{array}$ & $\begin{array}{l}28.4- \\
29.1 \\
\end{array}$ \\
\hline 6 & $\begin{array}{l}1.24 \\
(\mathrm{~m})\end{array}$ & 25.5 & $24^{\prime}$ & $\begin{array}{c}0.84 \\
(3 \mathrm{H}, \mathrm{t}) \\
\end{array}$ & 13.8 \\
\hline 7 & $\begin{array}{c}1.94 \\
(2 \mathrm{H}, \mathrm{m})\end{array}$ & 31.9 & 1" & $\begin{array}{c}4.14 \\
(1 \mathrm{H}, \mathrm{d})\end{array}$ & 103.4 \\
\hline 8,9 & $\begin{array}{c}5.37 \\
(2 \mathrm{H}, \mathrm{m})\end{array}$ & $\begin{array}{l}129.2, \\
130.2\end{array}$ & 2" & $\begin{array}{c}2.92 \\
(1 \mathrm{H}, \mathrm{m})\end{array}$ & 73.3 \\
\hline 10 & $\begin{array}{c}1.97 \\
(2 \mathrm{H}, \mathrm{m})\end{array}$ & 32.2 & 3" & $\begin{array}{c}3.15 \\
(1 \mathrm{H}, \mathrm{m}) \\
\end{array}$ & 76.4 \\
\hline $11-15$ & $\begin{array}{l}1.24 \\
(\mathrm{~m})\end{array}$ & $\begin{array}{l}28.4- \\
29.1 \\
\end{array}$ & 4" & $\begin{array}{c}3.03 \\
(1 \mathrm{H}, \mathrm{m})\end{array}$ & 69.9 \\
\hline 16 & $\begin{array}{l}1.24 \\
(\mathrm{~m})\end{array}$ & 31.2 & 5" & $\begin{array}{c}3.10 \\
(1 \mathrm{H}, \mathrm{m})\end{array}$ & 76.8 \\
\hline 17 & $\begin{array}{l}1.24 \\
(\mathrm{~m})\end{array}$ & 22.0 & 6" & $\begin{array}{c}3.44 \\
(1 \mathrm{H}, \mathrm{m})\end{array}$ & 60.9 \\
\hline 18 & $\begin{array}{c}0.84 \\
(3 \mathrm{H}, \mathrm{t})\end{array}$ & 13.8 & & $\begin{array}{c}3.66 \\
(1 \mathrm{H}, \mathrm{m})\end{array}$ & \\
\hline
\end{tabular}

\subsection{Compound 2}

Compound 2 was isolated in the form of colorless needles. Its ${ }^{1} \mathrm{H}$ and ${ }^{13} \mathrm{C}$ spectrum data were compared with those in the literature, and the results showed complete agreement with $\beta$-sitosterol [10].

\subsection{Compound 1 Inhibits Growth of Liver Cancer Cells}

The experiment results showed that exposure to 10,20 , 40 , or $80 \mu \mathrm{g} / \mathrm{L}$ compound 1 had an obvious inhibition effect on liver cancer cells. The growth of BEL-7402 cells exposed to any dose of compound 1 was significantly less than that of control cells $(\mathrm{P}<0.05)$. In addition, with increasing extract concentration and culture time the inhibitory effect was enhanced (Table 2).

Table 2. Growth inhibition on liver cancer BEL-7402 cell (inhibition rate, \%)

\begin{tabular}{|c|c|c|c|c|c|}
\hline \multicolumn{7}{|c|}{ Concentration of compound $1\left(\mu \mathrm{g} \cdot \mathrm{L}^{-1}\right)$} \\
\hline Times(h) & RPMI-1640 & 10 & 20 & 40 & 80 \\
\hline 24 & 0.0 & $7.6^{*}$ & $18.9^{* *}$ & $25.7^{* *}$ & $34.7^{* *}$ \\
\hline 48 & 0.0 & $16.8^{* *}$ & $26.4^{* *}$ & $38.9^{* *}$ & $45.9^{* *}$ \\
\hline 72 & 0.0 & $25.9^{* *}$ & $37.4^{* *}$ & $45.5^{* *}$ & $58.6^{* *}$ \\
\hline 96 & 0.0 & $37.9^{* *}$ & $46.3^{* *}$ & $59.1^{* *}$ & $85.4^{* *}$ \\
\hline
\end{tabular}

\subsection{Compound 1 Induces Apoptosis of Liver Cancer Cells}

After treatment with compound $1(40 \mu \mathrm{g} / \mathrm{L})$ for 24 hours, a percentage of liver cancer cells showed typical characteristics of apoptotic cells, such concentration and aggregation of chromatin on the perinuclear membrane, appearing as crescent globule (Figure 2).

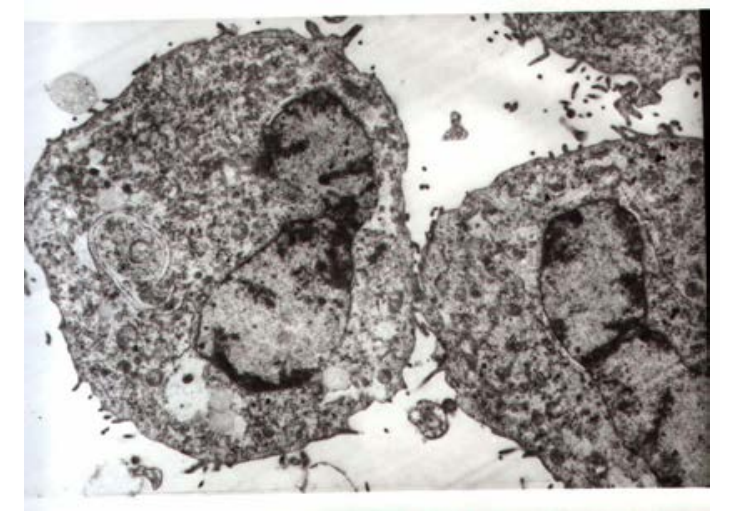

Figure 2. After treatment with compound 1, liver cancer cells were surrounded by a membrane structure formed by the nuclear fragments of apoptosis bodies (TEM, $\times 8000)$

\section{Conclusion}

We isolated two components with high purity from Weixian radish for the first time, and they were identified as and 1-O-( $\beta$-D-glucopyranosyl)-(2S, 3S, 4R, 8E)-2[(2'R)-2'-hydroxyl-tetracos-15'-enoyl- amino]-8-octadecene-1, 3, 4-triol and $\beta$-sitosterol. This is the first report on the cytotoxicity of glucocerebroside isolated from Weixian radish. 


\section{Acknowledgement}

No conflicts of interests have been declared. This study was supported by the Natural Science Foundation of Shandong Province (No. RZ2010CQ007, Y2006B27). All of the authors express their deep thanks.

\section{References}

[1] Zhang, X.C., Modern and Practical Anti-cancer Medicine. Beijing Science and Technology Press: Beingjing, China, 1999, 185-187.

[2] Li, S.Z., Graphic Compendium of Material Medical, Shanxi Normal University Press: Shan xi, China; 2007, 403.

[3] Wei, G.H., Zhao, P.J., Wan, C.Y., Tian, Y. and Li, G.F., "Root vegetables fruits-radish of medicinal value, method of storage and preserving the family", The First Academic Exchange Conference of the Medicated Diet and Health Proceeding, 187-188. 2009.
[4] Curtis, I.S., "The noble radish: past, present and future”, Trends in Plant Science, 8, 305-307. Jul. 2003.

[5] I. Blazevic, J., Mastelic, "Glucosinolate degradation products and other bound and free volatiles in the leaves and roots of radish (Raphanus sativus L.)”, Food Chemistry, 113, 96-102. Nov. 2009.

[6] Rumiana, K., Martin, C., "Phases and phase transitions of the sphingolipids”, Biochimica et Biophysica Acta, 1255, 213-236. May. 1995.

[7] Ryuichi, H., Masahiko, K., Tetsuya, K., "Structures of three new cerebrosides, astrocerebroside A, B, and C and of related nearly homogeneous cerebrosides", Liebigs Annalen der Chemie, 7, 659-663. 1991.

[8] Fattorusso, E., Mangoni, A., Progress in the chemistry of natural products. Springer Wien: New York, America, 1997, 72, 215-301.

[9] Pei, D., Liu, J.X. and Di, D.L., "Cerebroside and ceramide from the pollen of Brassica napus L”, Fitoterapia, 81, 838-843. Oct. 2010.

[10] Rubinstein, I., Goad, L.J., Clagueb, A.D.H. and L. J. Mulheirn, "The $220 \mathrm{MHz}$ NMR spectra of phytosterols", Phytochemistry, 15, 195-200. Jan. 1976. 